\title{
Statistics and outlook of primary hepatic angiosarcoma based on clinical stage
}

\author{
I-HSUAN HUANG ${ }^{1}$, YI-YING WU ${ }^{2}$, TZU-CHUAN HUANG ${ }^{2}$, WEI-KUO CHANG ${ }^{3}$ and JIA-HONG CHEN ${ }^{2,4}$ \\ ${ }^{1}$ Department of Medicine; Divisions of ${ }^{2}$ Hematology and Oncology, and ${ }^{3}$ Gastroenterology, Tri-Service General Hospital, \\ National Defense Medical Center, Taipei 114; ${ }^{4}$ Graduate Institute of Clinical Medicine, \\ College of Medicine, Taipei Medical University, Taipei 116, Taiwan R.O.C.
}

Received December 24, 2014; Accepted February 24, 2016

DOI: $10.3892 / 01.2016 .4348$

\begin{abstract}
Hepatic angiosarcoma is a rare condition that has been associated with exposure to colloidal solutions of thorium dioxide, vinyl chloride, arsenic and radiation. Therapeutic guidelines have not been definitively established due to the small number of cases of this disease. The present study reviewed 28 cases of hepatic angiosarcoma from studies that had been published between January 2000 and December 2012, in addition to 6 cases diagnosed at Tri-Service General Hospital (Taipei, Taiwan). Clinical staging was based on American Joint Committee on Cancer staging system for soft tissue sarcoma (2014). With a mean follow-up of 27.5 months (range, 0.27-102 months), 18\% (6/34) of the patients survived. The 1-, 3- and 5-year survival rates were 68.0 $\pm 9.3,42.1 \pm 10.2$ and $32.7 \pm 9.8 \%$ for patients with stage I disease (mean follow-up, 32.7 months), whilst the 1- and 3-year survival rates were $33.3 \pm 15.7$ and $22.2 \pm 13.9 \%$ for patients with stage IV disease (mean follow-up, 13.0 months). Determining an appropriate therapeutic strategy for this patient group is necessary. New studies encompassing larger patient populations are required in order to analyze and define standard prognostic parameters and to standardize a treatment approach for this extremely rare neoplasm.
\end{abstract}

\section{Introduction}

Angiosarcomas are uncommon tumors of endothelial-type cells that line vessel walls. These tumors account for $2-3 \%$ of adult soft tissue sarcoma cases (1), which are characterized by rapid proliferation and extensive infiltration. Soft tissue sarcomas may occur in any area of the body, typically the head and neck region or breast (2-4).

Correspondence to: Dr Jia-Hong Chen, Division of Hematology and Oncology, Tri-Service General Hospital, National Defense Medical Center,, No. 325, Section 2, Chenggong Road, Neihu, Taipei 114, Taiwan R.O.C.

E-mail:ndmc_tw.tw@yahoo.com.tw

Key words: hepatic angiosarcoma, staging, treatment, outcome
Hepatic angiosarcoma is an extremely rare condition, with only a small number of cases having been reported previously. It has been associated with exposure to colloidal solutions of thorium dioxide, vinyl chloride, arsenic and radiation $(5,6)$. Early hepatic angiosarcoma typically does not cause pain, and patients may exhibit no obvious symptoms (7). As the disease progresses, signs and symptoms may include abdominal fullness and abdominal pain (7).

Clinical staging of angiosarcoma is based on the American Joint Committee on Cancer (AJCC) staging system for soft tissue sarcoma (8). In addition to the size of the tumor and spread to lymph nodes or distant sites, the histological grade, based on cellular differentiation, mitotic rate and degree of necrosis, may be recorded for such patients (8). However, little has been established regarding the optimal treatment and outcomes according to disease stage. Various kinds of treatments, including surgery, chemotherapy and radiation, have been used previously, with varying outcomes (9-11). The overall 1-year, 3-year and 5-year survival rates associated with surgical treatment were $100.0,80.0$ and $40.0 \%$ based on a retrospective analysis of 6 cases (10). Studies focusing on the efficacy of systemic chemotherapy are limited; however, a study of 4 patients indicated that chemotherapy may improve quality and duration of survival (11). The present study reviewed 28 cases of hepatic angiosarcoma from studies published between January 2000 and December 2012, in addition to 6 cases diagnosed at our center, Tri-Service General Hospital (Taipei, Taiwan). Information was registered and analyzed for all 34 patients regarding initial stage, treatment and prognosis, with the aim of evaluating the association between tumor stage (according to the current staging system) and prognosis.

\section{Patients and methods}

Patients and study design. A review of the available literature on PubMed was conducted using the following key words: 'Liver angiosarcoma', 'hepatic angiosarcoma' or 'hepatic hemangiosarcoma'. Articles published between January 2000 and December 2012 and with available clinical data were included in the analysis. In addition, 6 cases diagnosed at Tri-Service General Hospital in the most recent 10 years were included. All cases contained detailed patient information, including medical history, tumor size, pathological diagnosis, 


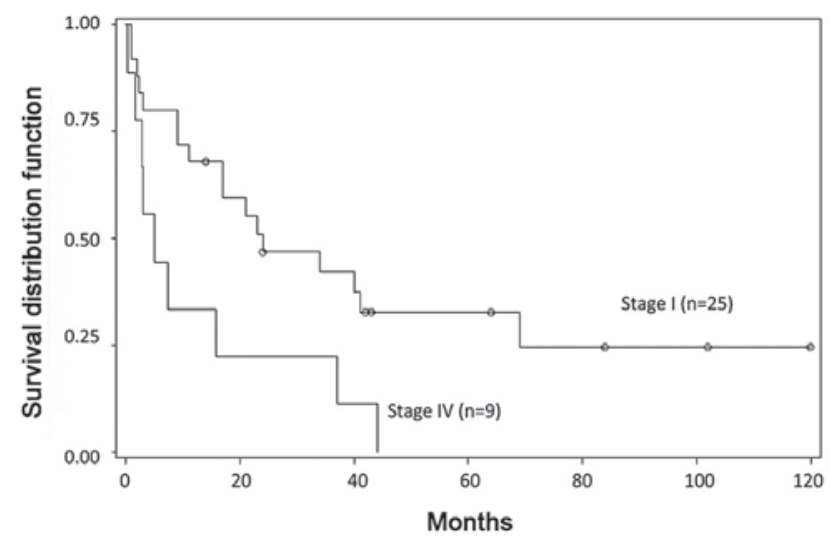

Figure 1. Overall survival of 34 patients in relation to tumor-node-metastasis stage $(\mathrm{P}=0.0157)$.

treatment records and prognosis. Clinical stage was based on the AJCC staging system (8). All cases were stage T1b or T2b, indicating deep tumors, as hepatic angiosarcoma is located beneath the superficial fascia. Histological grade will be determined as 'grade cannot be assessed' if tumor grade is not mentioned. Studies were excluded if tumor stage could not be determined on the basis of the published information. The presence of vascular invasion within the tumor and the number of tumors was also noted. Due to the tumor location in the liver, overall survival was assessed in relation to the TNM staging system for hepatocellular carcinoma (12).

Statistical analysis. Survival analysis was conducted using the Kaplan-Meier method and the log-rank test. Data were analyzed using SPSS software version 21 (IBM SPSS, Armonk, NY, USA). $\mathrm{P}<0.05$ was considered to indicate a statistically significant difference.

\section{Results}

Patient characteristics. A total of 65 cases of primary hepatic angiosarcoma were identified in the literature, of which 37 were excluded due to inadequate staging information, such as tumor size. In addition, 6 cases from Tri-Service General Hospital were included. Finally, 34 patients in 16 case reports and from our hospital were enrolled in the analysis $(10,13-27)$. The mean age at diagnosis was 58.9 years (range, $29-83$ years). The samples included 23 males and 11 females, giving a male:female ratio of $\sim 2: 1$ (Table I). This comprised 25 patients (74\%) with localized disease (stage I), and 9 patients (26\%) of an advanced stage (stage IV), with metastatic disease on presentation. The locations of extrahepatic metastasis included spleen, lung, bone, brain, stomach, peritoneum and pericardium.

Tumor size data was available for 25 patients. The mean size was $7.24 \mathrm{~cm}$, with a range of 2.4-20.0 cm. Histological grade was not mentioned for all cases. Treatment varied according to stage: The majority of patients with stage I disease (18 of 25 patients; $72 \%$ ) were initially treated with surgery; 1 case in our hospital received cyberknife treatment alone, whilst 3 cases received only supportive care (pain management, and nutritional and psychosocial support), including 2 cases in our hospital, due to poor performance status or

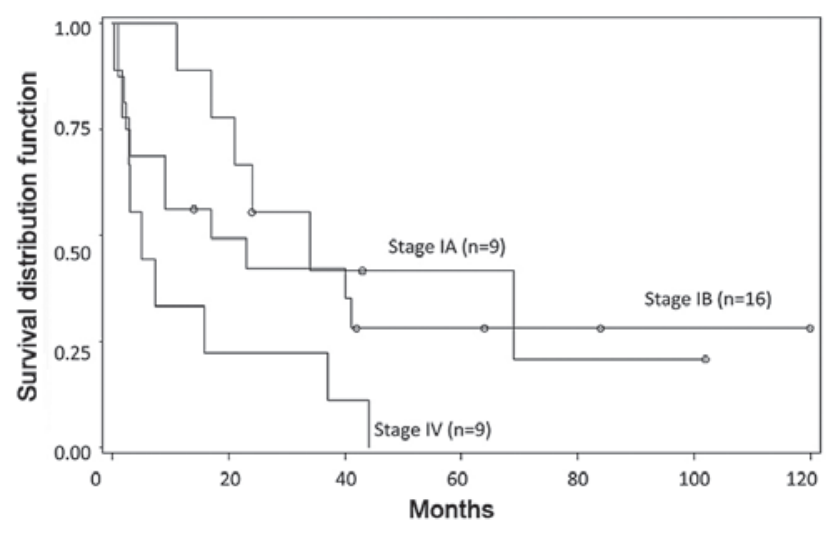

Figure 2. Overall survival of 34 patients in relation to tumor-node-metastasis stage of hepatic sarcoma. (IA vs. IB, $\mathrm{P}=0.4806$; IA vs. IV, $\mathrm{P}=0.0141$; IB vs. IV, P=0.0861).

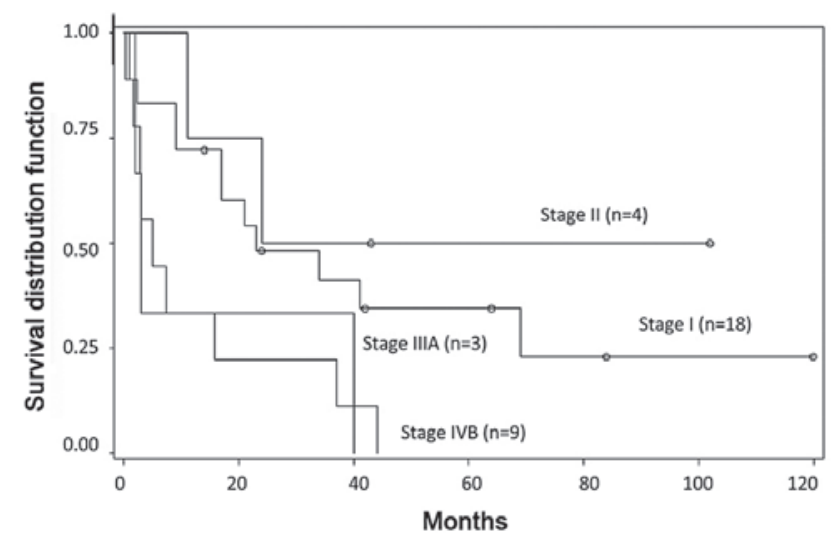

Figure 3. Overall survival of 34 patients in relation to tumor-node-metastasis stage of hepatic sarcoma, using the hepatocellular carcinoma staging system (I vs. II, $\mathrm{P}=0.4743$; I vs. IIIA, $\mathrm{P}=0.1487$; I vs. IVB, $\mathrm{P}=0.0182$; II vs. IIIA, $\mathrm{P}=0.1531$; II vs. IVB, $\mathrm{P}=0.0629$; IIIA vs. IVB, $\mathrm{P}=0.9972$ ).

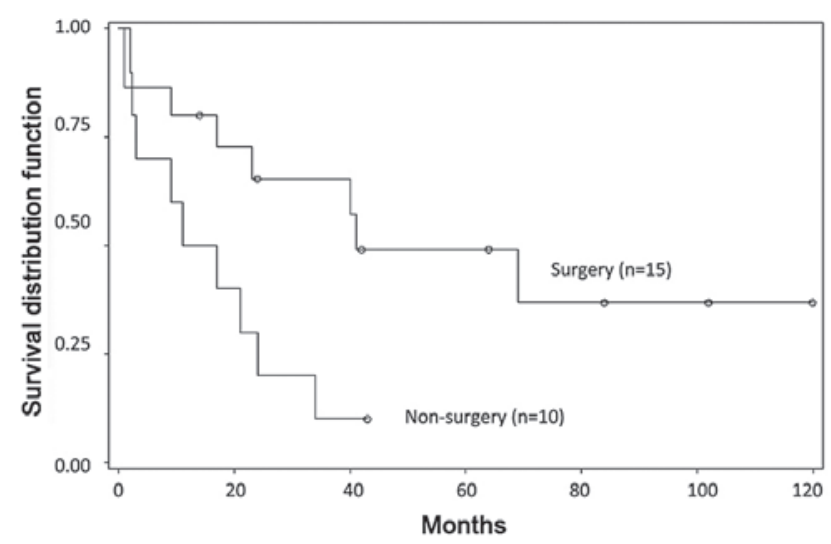

Figure 4. Overall survival of 25 patients with stage I hepatic angiosarcoma in relation to surgical status $(\mathrm{P}=0.0209)$.

advanced decompensated liver disease. Chemotherapy alone or combined surgery and chemotherapy was reported in 8 of 9 patients (89\%) with advanced stage disease (stage IV).

Survival outcome. Survival information was available in all cases. With a mean follow-up of 27.5 months (range, 


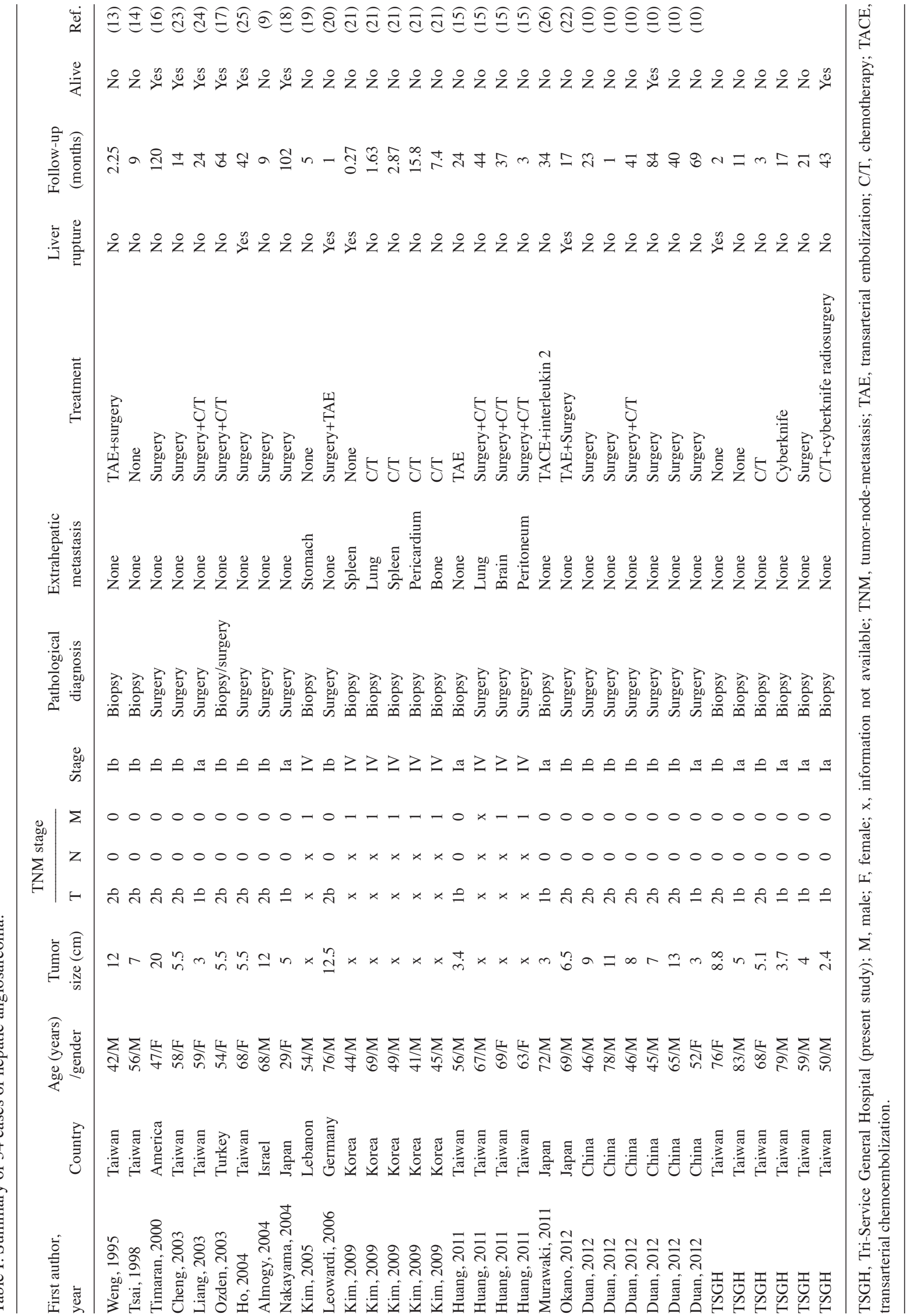


$0.27-102$ months), $18 \%(6 / 34)$ of the patients had survived. The

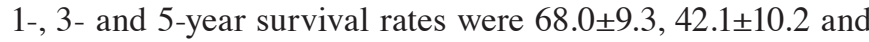
$32.7 \pm 9.8 \%$ in patients with stage I disease at diagnosis (mean follow-up, 32.7 months); for patients with stage IV disease, the 1- and 3-year survival rates were $33.3 \pm 15.7$ and $22.2 \pm 13.9 \%$ (mean follow-up, 13.0 months). Survival significantly differed between patients with stage I and with stage IV disease at presentation, based on Kaplan-Meier survival curves $(\mathrm{P}=0.0157)$; however, no apparent difference in survival was observed between those with stage IA and those with stage IB $(\mathrm{P}=0.4806)$. Thus, survival time worsened with advanced tumor stage at diagnosis compared with early stage at diagnosis (Figs. 1 and 2).

Staging system for hepatocellular carcinoma and survival outcome. According to the AJCC TNM staging system for hepatocellular carcinoma, 18 patients $(53 \%)$ had stage I disease, 4 patients $(12 \%)$ had stage II disease, 3 patients $(9 \%)$ had stage IIIA disease, and 9 patients (26\%) had stage IVB disease (Fig. 3). The overall survival of stages I and IVB was significantly different $(\mathrm{P}=0.0182)$; however, there was no statistically significant difference between any other two stages (I vs. II, $\mathrm{P}=0.4743$; I vs. IIIA, $\mathrm{P}=0.1487$; II vs. IIIA, $\mathrm{P}=0.1531$; II vs. IVB, $\mathrm{P}=0.0629$; IIIA vs. IVB, $\mathrm{P}=0.9972$ ). Thus, this did not appear to be superior to the staging system for sarcoma.

Treatment outcome. Survival rates were better for those who underwent site-directed surgery as part of first-line treatment than for those who did not $(\mathrm{P}=0.0209$; Fig. 4). The 1- and 3 -year survival rates of the non-surgery patient group in stage I were $50.0 \pm 15.8$ and $10.0 \pm 9.5 \%$, whilst the $1-$, 3 - and 5-year survival rates for patients in stage I who underwent surgery were $80.0 \pm 10.3,65.5 \pm 12.6,49.1 \pm 13.8 \%$.

\section{Discussion}

Primary vascular neoplasms of the liver are rare and have a poor prognosis (27). Tumor size, depth, presence or absence of regional lymph nodes, distant metastases and histological grade are commonly used to define the stage of soft tissue sarcomas (8). A size of $5 \mathrm{~cm}$ was the cutoff to determine tumor stage (IA or IB and IIA or IIB), based on the AJCC TNM staging system for soft tissue sarcoma (8). Superficial tumors are located exclusively above the superficial fascia without invasion of the fascia, whilst deep tumors are located in exclusively beneath the superficial fascia, not accounting for disease site (8). Thus, all hepatic angiosarcomas are considered deep tumors (8). Histological grading, which is based on cellular differentiation, mitotic rate and degree of necrosis, is an important component of staging, and has been demonstrated to be associated with degree of malignancy and the probability of distant metastasis (28). However, pathological grade information was absent in the cases included in the present study. T2 $(>5 \mathrm{~cm})$ tumors without spread to nearby lymph nodes (N0) or to distant sites (M0) with well-differentiated (G1) or grade information not available (GX) are classified as stage IB. However, if the tumor is poorly differentiated (G3) it is classified as stage III. Therefore, if definite tumor grade is taken into the consideration during cancer staging, individual treatment strategies can be developed and prognosis can be better predicted, possibly improving overall survival.

Typical computed tomography or magnetic resonance images of hepatic angiosarcoma reveal aggressive multifocal tumors containing small heterogeneous hypervascular foci, which had early arterial enhancement followed by progressive enhancement of the lesion compared with early and delayed phase imaging (29). In addition, the presence of positive nodes was not emphasized in cases reviewed in the present study. This may be because sarcomas rarely spread to regional lymph nodes. However, nodal metastasis has been reported in $13.5 \%$ of angiosarcomas (30). Early identification of lymph node involvement may result in appropriate disease management and positively affect outcomes. Thus, stage II and III of hepatic angiosarcoma are rare, and the majority of cases included in the current study were stage I or IV. It was difficult to predict the outcome due to the rarity of stage II and III cases.

There are several treatment options for hepatic angiosarcoma patients; surgery, chemotherapy and radiation have all been used previously, with varying outcomes (9-11). Complete surgical resection may provide an improved prognosis if the lesion is resectable (10). Responses to chemotherapy and radiation in advanced disease appear to be limited $(9,22)$; however, successful treatment with liver transplantation and chemotherapy has been reported (31). Furthermore, for patients with unresectable tumors or extrahepatic disease, chemotherapy may be considered (10). In the current analysis, the distribution of tumor stage at diagnosis was stage I or IV; this may be due to the absence of tumor grade in the included cases or the method of collecting samples; cases were excluded if there was no information regarding tumor size and staging was unavailable, but were included if the tumor had distant metastasis, when they were determined to be stage IV. This selection bias must be taken into account. However, the TNM stage at presentation without grade information in patients with hepatic angiosarcoma still appeared to be and important factor affecting prognosis. As the results of the Kaplan-Meier analysis demonstrated, patients in the early stages of disease at diagnosis had better overall survival times.

In addition, we attempted to use the AJCC TNM staging system for hepatocellular carcinoma to stage hepatic angiosarcoma. The number of tumors and the presence and extent of vascular invasion within the tumor were considered. However, compared with the soft tissue sarcoma staging system, there was no statistical association between stage and survival except for stages I and IVB.

Many unsolved issues remain regarding this type of cancer. In the previously published cases, standard prognostic parameters have not been consistently taken into account. In addition, different therapeutic strategies, treatment regimens and their outcomes have not been systemically evaluated.

In conclusion, hepatic angiosarcoma is a rare disease for which the therapeutic guidelines have not been defined due to the small number of cases. According to the current meta-analysis, patients with early-stage disease appear to have good prognosis following primary surgery or cyberknife therapy. Definitive diagnosis and clinical stage are important for initial assessment. Chemotherapy, surgery, radiation therapy or combined therapy were all considered. New studies encompassing larger patient populations are required to 
analyze and define standard prognostic parameters and to standardize a treatment approach for this rare neoplasm. The use of targeted therapies has markedly improved outcomes for certain types of cancer (32), and this may be important in the treatment of hepatic angiosarcoma in the future.

\section{References}

1. Lahat G, Dhuka AR, Hallevi H, Xiao L, Zou C, Smith KD, Phung TL, Pollock RE, Benjamin R, Hunt KK, et al: Angiosarcoma: Clinical and molecular insights. Ann Surg 251: 1098-1106, 2010.

2. Wanebo HJ, Koness RJ, MacFarlane JK, Eilber FR, Byers RM, Elias EG and Spiro RH; Society of Head and Neck Surgeons Committee on Research: Head and neck sarcoma: Report of the Head and Neck Sarcoma Registry. Head Neck 14: 1-7, 1992.

3. Blanchard DK, Reynolds CA, Grant CS and Donohue JH: Primary nonphylloides breast sarcomas. Am J Surg 186: 359-361, 2003.

4. Pandey M, Mathew A, Abraham EK and Rajan B: Primary sarcoma of the breast. J Surg Oncol 87: 121-125, 2004.

5. Buetow PC, Buck JL, Ros PR and Goodman ZD: Malignant vascular tumors of the liver: Radiologic-pathologic correlation. Radiographics 14: 153-166, 1994.

6. Ito Y, Kojiro M, Nakashima T and Mori T: Pathomorphologic characteristics of 102 cases of thorotrast-related hepatocellular carcinoma, cholangiocarcinoma and hepatic angiosarcoma. Cancer 62: 1153-1162, 1988.

7. Molina E and Hernandez A: Clinical manifestations of primary hepatic angiosarcoma. Dig Dis Sci 48: 677-682, 2003.

8. Edge SB, Byrd DR, Compton CC, Fritz AG, Greene FL and Trotti A (eds): AJCC (American Joint Committee on Cancer): Cancer Staging Manual. 7th edition. Springer, New York, p291, 2010.

9. Almogy G, Lieberman S, Gips M, Pappo O, Edden Y, Jurim O, Simon Slasky B, Uzieli B and Eid A: Clinical outcomes of surgical resections for primary liver sarcoma in adults: Results from a single centre. Eur J Surg Oncol 30: 421-427, 2004.

10. Duan XF and Li Q: Primary hepatic angiosarcoma: A retrospective analysis of 6 cases. J Dig Dis 13: 381-385, 2012.

11. Dannaher CL, Tamburro CH and Yam LT: Chemotherapy of vinyl chloride-associated hepatic angiosarcoma. Cancer 47: 466-469, 1981.

12. Edge SB, Byrd DR, Compton CC, Fritz AG, Greene FL and Trotti A (eds): AJCC (American Joint Committee on Cancer): Cancer Staging Manual. 7th edition. Springer, New York, p175, 2010.

13. Weng YJ, Chao Y, Wang SS, Chiang JH, Tsay SH, Chen CC, Chau GY, Lui WY and Lee SD: Hepatic angiosarcoma: Report of a case. Gastroenterol J Taiwan 12: 208-215, 1995.

14. Tsai CC, Cheng KS, Lai HC, Yu CJ and Hsu CH: Ruptured angiosarcoma of the liver treated by emergency TAE-case report. China Med Univ Reposit Taichung, 2007.

15. Huang NC, Wann SR, Chang HT, Lin SL, Wang JS and Guo HR: Arsenic, vinyl chloride, viral hepatitis and hepatic angiosarcoma: A hospital-based study and review of literature in Taiwan. BMC Gastroenterol 11: 142,2011.
16. Timaran $\mathrm{CH}$, Grandas $\mathrm{OH}$ and Bell JL: Hepatic angiosarcoma: Long-term survival after complete surgical removal. Am Surg 66: 1153-1157, 2000.

17. Ozden I, Bilge O, Erkan M, Cevikbaş U and Acarli K: Five years and 4 months of recurrence-free survival in hepatic angiosarcoma. J Hepatobiliary Pancreat Surg 10: 250-252, 2003

18. Nakayama H, Masuda H, Fukuzawa M, Takayama $T$ and Hemmi A: Metastasis of hepatic angiosarcoma to the gastric vein. J Gastroenterol 39: 193-194, 2004.

19. Kim TO, Kim GH, Heo J, Kang DH, Song GA and Cho M: Metastasis of hepatic angiosarcoma to the stomach. J Gastroenterol 40: 1003-1004, 2005.

20. Leowardi C, Hormann Y, Hinz U, Wente MN, Hallscheidt P, Flechtenmacher C, Buchler MW, Friess H and Schwarzbach MH: Ruptured angiosarcoma of the liver treated by emergency catheter-directed embolization. World J Gastroenterol 12: 804-808, 2006.

21. Kim HR, Rha SY, Cheon SH, Roh JK, Park YN and Yoo NC: Clinical features and treatment outcomes of advanced stage primary hepatic angiosarcoma. Ann Oncol 20: 780-787, 2009.

22. Okano A, Sonoyama H, Masano Y, Taniguchi T, Ohana M, Kusumi $\mathrm{F}$ and Nabeshima M: The natural history of a hepatic angiosarcoma that was difficult to differentiate from cavernous hemangioma. Intern Med 51: 2899-2904, 2012.

23. Cheng SP and Jeng KS: Hepatic angiosarcoma: Report of a case. Formos J Surg 36: 179-183, 2003.

24. Liang WB, Wang TE, Lin SC, Shin SC, Kao CR, Chou SY and Chang KM: Primary angiosarcoma of the liver - a case report. J Intern Med Taiwan 14: 290-294, 2003

25. Ho SY, Tsai CC, Tsai YC and Guo HR: Hepatic angiosarcoma presenting as hepatic rupture in a patient with long-term ingestion of arsenic. J Formos Med Assoc 103: 374-379, 2004

26. Murawaki Y, Kono M, Miura M, Sugihara T, Tanimura T, Oshima N, Tanaka S, Yoshimura T, Yamada M and Yoshida M: A case of hepatic angiosarcoma detected as a small lesion. Nihon Shokakibyo Gakkai Zasshi 108: 1252-1262, 2011 (In Japanese).

27. Groeschl RT, Miura JT, Oshima K, Gamblin TC and Turaga KK: Does histology predict outcome for malignant vascular tumors of the liver? J Surg Oncol 109: 483-486, 2014.

28. Fletcher CDM, Bridge JA, Hogendoorn PCW and Mertens F (eds): World Health Organization Classification of Tumours of Soft Tissue and Bone. 4th edition. IARC Press, Lyon, France, 2013.

29. Thapar S, Rastogi A, Ahuja A and Sarin S: Angiosarcoma of the liver: Imaging of a rare salient entity. J Radiol Case Rep 8: 24-32, 2014.

30. Fong Y, Coit DG, Woodruff JM and Brennan MF: Lymph node metastasis from soft tissue sarcoma in adults. Analysis of data from a prospective database of 1772 sarcoma patients. Ann Surg 217: 72-77, 1993.

31. Maluf D, Cotterell A, Clark B, Stravitz T, Kauffman HM and Fisher RA: Hepatic angiosarcoma and liver transplantation: Case report and literature review. Transplant Proc 37: 2195-2199, 2005.

32. Herrero AB, Martín-Castellanos C, Marco E, Gago F and Moreno S: Cross-talk between nucleotide excision and homologous recombination DNA repair pathways in the mechanism of action of antitumor trabectedin. Cancer Res 66: 8155-8162, 2006. 